\title{
Development of a Smartphone Program to Support Adherence to Oral Chemotherapy in People with Cancer
}

This article was published in the following Dove Press journal: Patient Preference and Adherence

\author{
Xiomara Skrabal Ross $\mathbb{D}^{1,2}$ \\ Kate M Gunn (D) 1,3 \\ Pandora Patterson (iD) 4,5 \\ lan Olver $\mathbb{D D}^{6}$
}

'Cancer Research Institute, University of South Australia, Adelaide, South Australia, Australia; ${ }^{2}$ School of Health Sciences, University of South Australia, Adelaide, South Australia, Australia; ${ }^{3}$ Department of Rural Health, University of South Australia, Adelaide, South Australia, Australia; ${ }^{4}$ Faculty of Nursing, Sydney Medical School, University of Sydney, Sydney, New South Wales, Australia; ${ }^{5}$ Research and Youth Cancer Services, CanTeen Australia, Sydney, New South Wales, Australia; ${ }^{6}$ Faculty of Health and Medical Sciences, University of Adelaide, Adelaide, South Australia, Australia
Correspondence: Kate M Gunn University of South Australia, City West Campus, HB Building, 8-25, Adelaide,

South Australia, Australia

$\mathrm{Tel}+61883022137$

Email kate.gunn@unisa.edu.au
Purpose: To describe the theoretical, evidence-based and consumer-informed development of a smartphone self-management program aiming to support adherence to oral chemotherapy in adolescents and adults diagnosed with cancer.

Methods: The design of the program followed two frameworks for the development and evaluation of mHealth interventions and was conducted in three steps: 1) conceptualization, which involved an extensive literature review and a scoping review that led to the identification of the behavioral change strategies in the program; 2) definition of features and structure, based on a formative study with end-users to explore their preferences about the structure and elements of the program; and 3) selection of program delivery technology, whereby available technology platforms were examined and the most suitable tool to deliver the program was selected.

Results: Three main reasons for oral chemotherapy non-adherence were identified: forgetfulness, side-effects and poor knowledge about oral chemotherapy. Key behavior change strategies were also identified, namely, medication intake reminders and information about oral chemotherapy and managing side-effects. Based upon end-user feedback the method of delivery of these behavioral strategies that was deemed most appropriate was conventional text messages. The reminders were standard, short, text-only messages sent when each oral chemotherapy dose was due, one way (no need to reply) and addressed the end-users using their first name. Delivery of information about oral chemotherapy and side-effects was tailored to each individual's preferred frequency.

Conclusion: The careful design process described in this paper may serve to inform the development of future mobile phone-based medication adherence-enhancing interventions for people with cancer. A trial to explore end-users acceptability of and satisfaction with the intervention is currently underway.

Trial Registration: ACTRN12618001987257p.

Keywords: oral chemotherapy, medication adherence, mobile phone, smartphone, text messages, cancer

\section{Background}

Oral chemotherapy (OC) drugs are increasingly being used in cancer treatment which allows patients and caregivers more independence in drug administration outside of hospital settings. However, these people with cancer are faced with the challenge of being responsible for self-managing their chemotherapy intake under less medical supervision. OC non-adherence can lead to health complications, including death. ${ }^{1}$ Despite this, disturbing rates of non-adherence to OC (up to $54 \%$ ) have been found among adults with cancer. ${ }^{2}$ In adolescents and young adults 
aged 16-25 y/o (AYA), OC non-adherence rates are yet to be established, but there is evidence of low medication adherence in AYA diagnosed with other chronic diseases such as human immunodeficiency virus, asthma, rheumatoid arthritis, epilepsy and diabetes mellitus. ${ }^{3-5}$

Adherence is defined as the extent to which a person's behavior in taking medicines corresponds with the agreed recommendations of the clinician. ${ }^{6}$ Although evidence on the minimum adherence rates required for the majority of OC drugs to achieve optimal outcomes is scarce, an adherence threshold of $80 \%$ or more has been consistently used in medication adherence research. ${ }^{7}$ One of the main challenges faced by $\mathrm{OC}$ users and oncology health professionals is the lack of standardized oncology practices to monitor and support OC adherence. ${ }^{8}$ This highlights the need to make self-management tools available to people prescribed $\mathrm{OC}$, in order to ensure that the way they take their medication is consistent with their doctors' recommendations. Due to evidence on low medication adherence in AYA with chronic medical conditions, this population may have an even greater need for OC adherence support programs than other age groups.

Given their widespread popularity and sophisticated features, mobile phones are proving to be promising tools to deliver medication adherence interventions to people with chronic diseases. ${ }^{9}$ However, evidence on the effect of mobile phone-based interventions on $\mathrm{OC}$ adherence is lacking. ${ }^{14}$

An intervention to support $\mathrm{OC}$ adherence should be suitable for integration into "real" oncology settings and suitable to be administered by existing, busy healthcare professionals. The design and evaluation of mobile phonebased health interventions involves considerable time, human and financial resources. Therefore, it is important that research on these types of interventions includes input from end-users and follows a standardized process to increase the chances of the intervention being efficacious and acceptable. ${ }^{10}$ Experts recommend that researchers facilitate public access to the development process of mHealth interventions to enable other investigators to understand the methods involved in the design. ${ }^{11}$ mHealth has been defined by the World Health Organization as the use of mobile devices (mobile phones, patient monitoring devices and other wireless technology) to support medical and health practices. ${ }^{12}$

\section{mHealth Frameworks}

In this study, two mHealth frameworks were used to guide the development of a novel smartphone text message program to support adolescents and adults with cancer in taking their $\mathrm{OC}$ as prescribed by their doctor: the Behavioral Intervention Technology (BIT) model ${ }^{13}$ and Whittaker et al's development and evaluation framework for mHealth interventions. ${ }^{10}$

Whitaker et al's development and evaluation framework for mHealth interventions ${ }^{10}$ was created to increase the understanding of best practice in the design of such interventions. This was in response to the lack of dissemination of formative research and intervention design studies prior to publication of most randomized controlled trials in mHealth. The framework recommends six steps: conceptualization, formative research, pre-testing, pilot study, randomized controlled trial and qualitative follow-up.

Further, the integration between behavioral and technological aspects of interventions is essential in the development of behavioral tools delivered via mobile phones and the internet that aim to achieve health-related goals through the use of evidence-based methods. This premise is the essence of the BIT model. ${ }^{13}$ The BIT model has two levels, the theoretical level which involves setting the clinical aims of the intervention or articulating "why" it needs to be developed, as well as the behavioral strategies needed to achieve the aims or the conceptual "how" of the model. The second level is known as the instantiation level. Instantiation is a term used in computer programming and involves the identification of concrete actions needed to deliver more general categories of strategies previously established (e.g. text message medication reminders as a behavioral change prompting strategy). This level refers to the elements of the intervention or the "what"; the technical details of how the elements are displayed (e.g. delivery mediums such as video, text, etc.) and the workflow of the elements in the intervention that determine exactly when each element will be deployed.

\section{Purpose of the Study}

The creation of the program outlined in this paper addresses the aforementioned pressing need for OC users to be supported in self-managing drug administration. It builds upon the promise shown by mHealth in improving adherence to medications for the treatment of other chronic diseases ${ }^{9}$ and addresses the dearth of evidence on the efficacy of mobile phone-based interventions in increasing adherence to OC. ${ }^{14}$ More specifically, this paper describes the first phase in the development of a smartphone text message self-management program to support adherence to $\mathrm{OC}$ in adults and adolescents affected 
by cancer. It consists of three steps: conceptualization of the program, definition of the features and structure of the program and selection of the technology used to deliver the program. Acceptability and satisfaction with the intervention will be explored in a pilot proof-of-concept trial which is currently underway.

\section{Step I. Conceptualization of the Program}

This step led to definition of the clinical and usage aims of the program and identification of behavioral change strategies incorporated into the intervention in order to achieve its objectives. In order to do this, an extensive literature review on key reasons for OC non-adherence that have the potential to be modified by a mobile phonebased intervention was conducted. This was followed by a scoping review that explored what was known about available mobile phone-based interventions to increase adherence to OC, the reported usability of those interventions and opportunities for future research $\left(\mathrm{see}^{14}\right)$.

The selection of behavioral change strategies was also guided by evidence showing that medication adherence is a multi-factorial phenomenon, which makes it difficult to generate a matrix of determinants to predict individual medication adherence. ${ }^{15}$ Therefore, this intervention should focus on addressing multiple variables that effect adherence behavior.

\section{Methods}

A database search of Medline, Embase, Emcare and PsychINFO was conducted to find systematic reviews on determinants of non-adherence to OC. Inclusion criteria for this search were: a) follow a systematic review approach, b) containing reasons/determinants/factors for oral chemotherapy/oral endocrine therapy non-adherence, and c) be written in English. The search started with systematic reviews because they account for methodical revisions and reports on existing evidence up to the last date searched. The most recent systematic review was published in 2016 and covered evidence until June $2015 .^{2}$ Two additional systematic reviews were found $d^{7,16}$ and were included in the review. In order to add more recent evidence to this review, a second database search was conducted for a) research-based studies, b) containing reasons for oral chemotherapy/oral hormonal therapy non-adherence, c) written in English and d) published between June 2015 and March 2018. Two relevant studies were identified ${ }^{17,18}$ and incorporated into the literature review.

Three main reasons for non-adherence to OC (with the potential to be modified by a mobile phone-based intervention) were found to be: 1) forgetfulness, 2) side-effects and 3) poor knowledge about oral chemotherapy. An in-depth examination into the reviewed studies facilitated selection of behavior change strategies that had been found to be useful in addressing the key barriers to OC adherence, with no evidence on their previous integration into a text messagebased program for OC users. Table 1 summarizes these key reasons and corresponding behavior change strategies.

Findings from the second review in this step (scoping review) have been published elsewhere. ${ }^{14}$ The review identified five papers reporting on four interventions. The interventions, delivered via mobile phone short message service (SMS), commonly known as text messages, apps or a combination of both, were deemed by their users as highly acceptable and usable. The review highlighted a lack of SMS-based interventions incorporating strategies to address the three previously identified key reasons for OC non-adherence and the scarcity of mobile phone-based interventions to support AYA in adhering to their OC prescriptions. The importance of following a development framework for mHealth interventions and engaging end-users in intervention development were also highlighted by the review.

Table I Key Reasons for Oral Chemotherapy (OC) Non-Adherence and Potentially Effective Behavior Change Strategies to Address Barriers

\begin{tabular}{|l|l|l|l|}
\hline $\begin{array}{l}\text { Main Reason for OC } \\
\text { Non-Adherence }\end{array}$ & Reference & Potentially Effective Behavior Change Strategy & Reference \\
\hline Forgetfulness & {$[7,16,18]$} & $\begin{array}{l}\text { Text message-based medication intake reminders (evidence only in other chronic } \\
\text { diseases) }\end{array}$ & {$[19]$} \\
\hline Side-effects & {$[2,16-18]$} & $\begin{array}{l}\text { Information to manage challenges related to side-effects (evidence on its } \\
\text { effectiveness only as part of multi-strategy interventions) }\end{array}$ & {$[18,20-23]$} \\
\hline $\begin{array}{l}\text { Poor knowledge about oral } \\
\text { chemotherapy treatment }\end{array}$ & {$[7,16]$} & $\begin{array}{l}\text { Information about OC treatment (evidence on its effectiveness only as part of } \\
\text { multi-strategy interventions) }\end{array}$ & {$[18,20,24]$} \\
\hline
\end{tabular}




\section{Step 2. Definition of the Features and Structure of the Program}

This step consisted in the identification of the technical elements (eg, notifications, messaging, reports) included in the program in order to deliver the behavior change strategies to users.

The technical characteristics of the intervention (eg, the platform used to deliver the strategies, personalization of the strategies) and the frequency and conditions of intervention delivery (eg, frequency of medication reminders) were defined in this step. The selection of the program's features and structure was informed by findings from a formative study (conducted by the research team) which explored patients' preferences about the structure and elements in a smartphone self-management program to support adherence to OC. This study is outlined in the following paragraph. The most suitable sources and structure of information to be incorporated into the program were identified through a literature review.

\section{Methods}

Nine people diagnosed with cancer, who had experience taking OC, were involved in the formative qualitative study. Data were collected via semi-structured phone interviews. Participants were aged 20-69 years, 78\% male and 22\% female, and treated for diverse cancer types in South Australian hospitals. Sixty-seven per cent of the participants were in active treatment with OC and 33\% had their last OC dose up to 18 months before the study commenced. Data were analysed using Thematic Analysis. ${ }^{25}$ Data saturation was reached for most of the topics explored.

Findings included that participants preferred a short standard SMS medication reminder, delivered via conventional mobile phone SMS (instead of other messaging apps such as Facebook messenger and Whatsapp). This SMS should be consisting of text-only, one-way communication (no need for users to reply) which was personalized with their first name. Information about OC and side-effect management was deemed by the participants to be too long to be sent in a conventional SMS, which only allows for 160 characters. There was a preference for these strategies to be delivered by an SMS hyperlink to a Portable Document Format (PDF) file. Participants' preference for their OC intake reminder SMS was 15 mins before the OC dose was due. Since OC schedules vary between individuals, it became apparent that the timing of SMS delivery needed be tailored to each individual's medication prescription.

The formative study did not find consistency in OC users' preferences on the frequency of delivery of information about $\mathrm{OC}$ and side-effects management. These findings suggest that tailoring the frequency of delivery for both strategies to individual end-users' preferences may be the most suitable option. Study participants were asked to provide examples of what they would like their SMS reminders to say. These examples allowed the creation of the following standard SMS: "Please take your oral cancer medication now. If you need further support, let us know and we will be happy to help (name and phone hospital contact)".

In addition to the formative study, procedures were undertaken to help define the program's content structure. The content of the strategy "information about oral chemotherapy" was an extract from the education section of the eviQ website (www. eviq.org.au), which is a national resource of evidence-based cancer treatment protocols and was recommended to the research team by oncology healthcare professionals (clinicians and nurses) in five Australian hospitals. In this step, the guidelines for drug-specific education in the MOATT (Multinational Association for Supporting Care in Cancer MASCC Teaching Tool for Patients Receiving Oral Agents for Cancer) ${ }^{26}$ were used to determine the availability of information on the eviQ website and the content that needed to be incorporated from other information sources. This process led to the definition of the structure of the content of the "Information about oral chemotherapy" strategy that served as a guide for posterior development of tailored information to each end user's OC prescription. Table 2 shows the content present and not present on the eviQ website according to MOATT's guidelines.

The content in the "information about managing sideeffects" strategy was informed by a literature review (conducted by the research team) in which the Symptom Management Toolkit ${ }^{27}$ was identified to be potentially effective in reducing the presence and severity of symptoms in patients taking OC. Due to the length of the tool (93 pages) and the American English employed, the Toolkit was reviewed by an experienced oncologist (IO) and two research psycho-oncologists (XSR, KG) to adapt its structure to be mobile phone-friendly, relevant to Australian OC users and suitable to the purposes of the self-management program. Some of the toolkit's characteristics were deemed by the reviewers to not be suitable for the purposes of the program (see Supplementary file).

\section{Step 3. Selection of Program Delivery Technology}

Together with step 2, this step aimed to answer questions related to the technical elements of the program defined as 
Table 2 Information on the EviQ Website Patient Education Section, Based on the MOATT Guidelines for Drug-Specific Education

\begin{tabular}{|c|c|c|c|}
\hline Information & MOATT Guidelines & $\begin{array}{l}\text { Information Present in eviQ } \\
\text { Website }\end{array}$ & $\begin{array}{l}\text { Information Not } \\
\text { Present in eviQ Website }\end{array}$ \\
\hline Drug name & To provide generic and trade drug name & Generic name & Trade name \\
\hline $\begin{array}{l}\text { Drug dose and } \\
\text { schedule }\end{array}$ & $\begin{array}{l}\text { To provide information about: } \\
\text { What the drug looks like } \\
\text { How many different pills are to be taken? } \\
\text { How many times a day should be taken? } \\
\text { For how long should it be taken? }\end{array}$ & $\begin{array}{l}\text { How many different pills are to be taken } \\
\text { How many times a day should be taken? } \\
\text { For how long should it be taken? }\end{array}$ & What the drug looks like \\
\hline $\begin{array}{l}\text { Where to store } \\
\text { pills or tablets }\end{array}$ & $\begin{array}{l}\text { How should I store it? To be specific, for example away } \\
\text { from the heat (not in the kitchen), away from humidity } \\
\text { (not in the bathroom), away from the sun (not under } \\
\text { a window) }\end{array}$ & & How to store medication \\
\hline $\begin{array}{l}\text { Potential side } \\
\text { effects and how } \\
\text { to manage them }\end{array}$ & $\begin{array}{l}\text { To include information about potential side-effects and } \\
\text { how to manage them. Also to include lab evaluations or } \\
\text { any medical tests that will be used for drug monitoring }\end{array}$ & $\begin{array}{l}\text { Potential side effects and how to } \\
\text { manage them }\end{array}$ & $\begin{array}{l}\text { Lab evaluations or any } \\
\text { medical tests that will be } \\
\text { used for drug monitoring }\end{array}$ \\
\hline $\begin{array}{l}\text { Any drug or food } \\
\text { interactions }\end{array}$ & $\begin{array}{l}\text { Is it safe to take it with other drugs, food, vitamins, } \\
\text { herbs, supplements, or other treatments I use? }\end{array}$ & $\begin{array}{l}\text { General drug, herbs and medication } \\
\text { interactions. Information on what to } \\
\text { report to the doctor }\end{array}$ & \\
\hline $\begin{array}{l}\text { When and } \\
\text { whom to call } \\
\text { with questions }\end{array}$ & $\begin{array}{l}\text { To provide information on how the patient can get in } \\
\text { touch with treating team if having trouble late at night } \\
\text { or on the weekend }\end{array}$ & $\begin{array}{l}\text { Information on when to go to } \\
\text { emergency and what information to } \\
\text { collect from their treating team. }\end{array}$ & $\begin{array}{l}\text { Hospital-specific } \\
\text { emergency contact details }\end{array}$ \\
\hline
\end{tabular}

Note: Data from Kav et al. ${ }^{26}$

the "how" (technical) instantiation component in the BIT model. ${ }^{13}$

The fit between the available technology options and the practical demands of the program guided the selection of the most appropriate technology for program delivery. The program requirements were to be accurate in SMS delivery at the date and time intended, to allow automatization of SMS delivery, to offer high levels of security to protect users' contact details, to allow data entry does that not pose a time burden and to be cost-effective (in order to increase the chance of translation into real oncology settings). To meet these demands, a solution consisting of an automated SMS gateway (a platform that allows pre-scheduling of the SMS and delivers them automatically) was considered ideal. Two options were compared: an information technology (IT) solution developed specifically for the purposes of the program and available secure websites. Table 3 shows a comparison between the two options.

The comparison between the two SMS technology options showed that while both alternatives seemed to be accurate in SMS delivery and highly secure, available secure websites had the following advantages over the tailored IT solution: saving development time, avoiding the possibility of system issues requiring specialist IT support, and a lower cost. Therefore, this option was selected and explored further by testing two websites that appeared to meet the practical demands of the program. After a one-month trial of the two websites, one of them showed issues with SMS delivery accuracy, consistently delivering SMS at the wrong time, so this option was eliminated.

Google Drive (an online file storage system) was employed to save information about $\mathrm{OC}$ and side-effects in PDF format. Google Drive is secure (passwordprotected), free of charge and document hyperlinks can easily be shared via SMS.

\section{Results}

The three steps previously described allowed the development of a smartphone text message self-management program to support adherence to $\mathrm{OC}$ in adolescents and adults with cancer.

The clinical aim of the program was to support users to maintain or increase their $\mathrm{OC}$ adherence rates at a level equal to or higher than $80 \%$ (percentage of OC prescribed doses $/ \mathrm{OC}$ doses taken) during the time of program delivery. The usage aim 
Table 3 Comparison Between a Tailored Information Technology Solution and Available Secure Websites for Delivery of Text Messages in the Program

\begin{tabular}{|l|l|l|}
\hline $\begin{array}{l}\text { Technology } \\
\text { Characteristics }\end{array}$ & Tailored IT Solution & Available Secure Websites \\
\hline $\begin{array}{l}\text { Cost (Au\$, based on } \\
3500 \text { SMS) }\end{array}$ & $9000-13,000$ (total cost of SMS Au\$287 included) & 287 (0.082 per SMS) \\
\hline Time & $\begin{array}{l}3 \text { months development-solution may present fails needing IT } \\
\text { support, less researchers' time required for manual data entry } \\
\text { as a database is linked to the SMS gateway }\end{array}$ & $\begin{array}{l}\text { No time to develop- slightly more researchers' time } \\
\text { rexternal database. }\end{array}$ \\
\hline $\begin{array}{l}\text { Security (confidentiality } \\
\text { terms and security } \\
\text { software packages) }\end{array}$ & High & High \\
\hline $\begin{array}{l}\text { Accuracy (SMS delivery at } \\
\text { the intended time and day) } \\
\text { SMS automatization }\end{array}$ & High & High \\
\hline
\end{tabular}

of the program was defined as end-users' high acceptability of and satisfaction with the program. Behavioral change strategies that may positively impact on three key reasons for OC nonadherence were defined and categorized according to Michie et al's Behavior Change Technique Taxonomy ${ }^{28}$ which provides a consensual structure to report behavior change interventions. These behavioral strategies are:

- Prompts: medication intake reminders sent via text messages, to reduce forgetfulness in taking OC doses. Category $7.1^{28}$

- Instruction on how to perform the behavior: information about strategies to manage OC-related sideeffects, to reduce symptom severity. Category $4.1^{28}$

- Instruction on how to perform the behavior: information about individual OC treatment, to increase knowledge about OC. Category $4.1^{28}$
The features of the program were identified based on findings from the formative qualitative research described in Step 2 of this paper. Table 4 schematizes the structure of the program based on the BIT model. ${ }^{13}$

\section{Proof-of-Concept Trial of the Program}

A pilot, proof-of-concept trial of the intervention described in this paper is currently being conducted at six Australian hospitals. All relevant ethics and governance approvals were obtained. Australian New Zealand Clinical Trial Registry number (ACTRN): ACTRN12618001987257p. The aim of the study is to explore whether participants' find the intervention acceptable and whether they are satisfied with it. The study was designed as a 10 -week non-randomized trial with participants aged 16-75 years, receiving OC (non-endocrine) drugs, who own a smartphone and are willing to receive and read SMS

Table 4 Structure of the Program Developed Based on Evidence and Formative Research, According to the BIT Model

\begin{tabular}{|l|l|l|l|}
\hline $\begin{array}{l}\text { Instantiation } \\
\text { Component }\end{array}$ & What & How (Technical) & When \\
\hline $\begin{array}{l}\text { BIT } \\
\text { Component }\end{array}$ & Elements & Characteristics & Workflow \\
\hline $\begin{array}{l}\text { Intervention } \\
\text { component }\end{array}$ & $\begin{array}{l}\text { (a) Reminders to take } \\
\text { medication } \\
\text { (b) Information about oral } \\
\text { chemotherapy } \\
\text { (c) Information about } \\
\text { managing side-effects }\end{array}$ & $\begin{array}{l}\text { (a) Standard (text-only) reminders to take medication } \\
\text { delivered via SMS. SMS are one-way (no need to reply) } \\
\text { and personalized with users' name } \\
\text { (b) Information delivered in SMS hyperlink to PDF } \\
\text { online document } \\
\text { (c) Information delivered in SMS hyperlink to PDF online } \\
\text { document }\end{array}$ & $\begin{array}{l}\text { (a) Delivered I5 mins before due oral } \\
\text { chemotherapy dose intake. Frequency } \\
\text { tailored to individuals' prescription. } \\
\text { (b) Delivered at the frequency pre-selected } \\
\text { by each individual } \\
\text { (c) Delivered at the frequency pre-selected } \\
\text { by each individual }\end{array}$ \\
\hline
\end{tabular}

Note: Data from Mohr et al. ${ }^{13}$ 
texts. Adherence to OC is being assessed through medication event monitoring devices (MEMS) and a self-report questionnaire. Other endpoints of the study are: knowledge of oral chemotherapy, the occurrence and severity of symptoms and satisfaction with the intervention. Participants' socio demographic data are also being collected. Findings from the trial will determine the feasibility of the intervention, as well as further refinements needed to progress to a randomized controlled trial.

\section{Discussion}

The development process of a novel smartphone selfmanagement program that aims to support oral chemotherapy (OC) adherence in adolescents and adults was described. The program's design addresses two main gaps: the lack of mHealth interventions to support adherence to OC and the scarcity of these types of interventions to support AYA in adhering to their OC prescriptions (likely to be an at-risk group). ${ }^{14}$

The design was informed by evidence that forgetfulness, side-effects and poor knowledge about oral chemotherapy are the key reasons for OC non-adherence that have potential to be modified by a mobile phone-delivered intervention. Also, it was recognised that that SMS reminders to take OC, as well as information about oral chemotherapy and its side-effects, are potentially effective strategies to address the factors determining non-adherence. Whittaker et al's model ${ }^{11}$ provided a methodological framework for the design of the program, and the BIT model ${ }^{13}$ provided a theoretical structure for program development.

Oral chemotherapy users were also engaged in the design process via formative research, in which their preferences about the structure and elements of program were explored. This is particularly important as the final objective of an intervention of this type (once its efficacy has been established) is that it is highly accepted by its endusers and translatable into "real" oncology settings. Should the proof-of-concept trial show that the program is useable, it could easily be made available to help people with cancer to adhere to their OC schedules as the system is easy and cost-effective for health professionals to use.

Importantly, oncology healthcare teams (clinicians, nurses and pharmacists) from five out of six of the Australian hospitals were engaged at all steps of the development by providing their feedback and suggestions about the structure and content of the program. Healthcare teams' suggestions shape the design of the intervention. For example, they suggested eviQ as the most suitable and reliable information source for OC treatment and they informed the research team about the characteristics of OC schedules which helped in making decisions about individual tailoring of the frequency of SMS reminders to take medication and the content of information in the program.

The design of the program took approximately one and a half years. However, this is an iterative process as the current pilot proof-of-concept trial (underway) will provide additional information on possible further program refinements that may improve acceptability and user satisfaction.

The program's trial involves a heterogeneous sample of patients with various cancer types and OC drugs. Additionally, while a number of intervention features are set to be tailored to the user (eg, time of drug intake, frequency of delivery of SMS with information), other features are general to all users (eg, content of SMS reminders) or users taking specific drugs (information about oral chemotherapy and side-effects). Findings from the proof-of-concept trial will inform the suitability of the program to different cancer types and OC drugs and, if available, areas of opportunity for tailoring of additional intervention features will be highlighted.

This paper addresses' experts' recommendations to make contributions to the literature that detail the development process of mHealth interventions. ${ }^{11}$ The process described here could be used to guide the methodological design of future OC adherence interventions delivered via mobile phones.

\section{Limitations and Directions for Future Research}

The formative study which informed part of the program's design used qualitative methods. While data saturation was reached for most of the topics explored and findings may serve as a reference for the design of future-related research, intervention-specific formative research is highly encouraged. A limitation of this study is that, although the literature reviews conducted in the design process described were extensive and systematic, their findings do not discriminate between studies with poor methodology or with restricted generalization of findings, as it is the case in systematic reviews that use more rigorous methodology.

One of the strengths of the design process described in this paper is its potential to be highly relevant to end-users and be translatable into oncology settings. The program was developed based on evidence, it was informed by theoretical 
and development mHealth frameworks, and importantly, end-users and oncology health professionals were engaged in the process. Additionally, this program addresses gaps in the literature such as the unavailability of SMS-based interventions that incorporate strategies to manage the key reasons for OC non-adherence and the scarcity of these types of interventions for younger people with cancer. ${ }^{14}$

It has been suggested that the development and evaluation (including a randomized controlled trial) of mHealth interventions takes between three and four years to be completed. ${ }^{10}$ This may be too long for interventions based on technology, which evolves rapidly affecting the usability of the tools. In order to keep up to date with technology changes, it is recommended that the evaluation of interventions incorporate qualitative methods to explore further refinements including changes in the technology platforms used. ${ }^{10}$ The development of this program took longer than was initially planned (six additional months) due to challenges in the recruitment of participants to the formative research. Similar delays may be also experienced in the pilot proof-of-concept trial of the program. It is important for future research to take into account the time span involved in the creation of mHealth interventions and adequately plan for it.

The design process described in this study may inform the development of future mobile phone-delivered interventions to support OC adherence.

\section{Conclusions}

This study described the development process of a smartphone text message self-management program to support OC adherence in adolescents and adults with cancer. Evidence about gaps in the literature, the main reasons for $\mathrm{OC}$ non-adherence and strategies to positively affect those factors, as well as mHealth design and theoretical frameworks informed the process. Oral chemotherapy end-users and oncology healthcare professionals were engaged during the design to increase the odds of the program being accepted by end-users and translatable into oncology settings. A proof-ofconcept trial is now being conducted to explore whether the intervention is acceptable to adolescents and adult OC users and they are satisfied with the outcomes.

\section{Ethics Approval and Consent to Participate}

The formative research was approved by the following Human Research Ethics Committees: Womens' and Children's' Hospital (HREC/17/WCHN/52) and the University of South
Australia and Central Adelaide Local Health Network (South Australia). Participants provided written informed consent and the study was conducted in accordance with the Declaration of Helsinki.

\section{Acknowledgments}

The authors gratefully acknowledge the collaboration of the Leukaemia Foundation and CanTeen Australia/Youth Cancer Services SA/NT. The authors also acknowledge the Michigan State University's contribution by granting the research team's access to the Symptom Management Toolkit. An abstract of this paper was presented at the MASCC/ISOO 2019 Annual Meeting as a poster presentation with interim findings. The poster's abstract was published in "Poster Abstracts" in Supportive Care in Cancer; 2019;27(S1):1 (https://doi.org/10.1007/s00520-019-04813-1).

\section{Author Contributions}

All authors contributed to data analysis, drafting or revising the article, gave final approval of the version to be published, and agree to be accountable for all aspects of the work.

\section{Funding}

Funding for this development study was supported by the Cancer Research Institute, University of South Australia.

\section{Disclosure}

The authors report no conflicts of interest in this work.

\section{References}

1. Thompson AM, Dewar J, Fahey T, et al. Association of poor adherence to prescribed tamoxifen with risk of death from breast cancer. Proceedings of the American Society of Clinical Oncology Breast Cancer Symposium; 2007; San Francisco.

2. Greer J, Amoyal N, Nisotel LE, et al. A systematic review of adherence to oral antineoplastic therapies. Oncologist. 2016;21(3):354-376. doi:10.1634/theoncologist.2015-0405

3. Kim SH, Gerver SM, Fidler S, Ward H. Adherence to antiretroviral therapy in adolescents living with HIV: systematic review and meta-analysis. AIDS. 2014;28(13):1945-1956. doi:10.1097/QAD.0000000000000316

4. Kyngas H. Compliance of adolescents with chronic disease. J Clin Nurs. 2000;9(4):549-556. doi:10.1046/j.1365-2702.2000.00368.x

5. Kyngas H. Compliance with health regimens of adolescents with epilepsy. Seizure. 2000;9(8):598-604. doi:10.1053/seiz.2000.0470

6. World Health Organization. Adherence to Long-Term Therapies: Evidence for Action. Internet. In: Sabaté E, editors. World Health Organization; 2003. Available from: http://www.who.int/iris/handle/ 10665/42682. Accesed February 2018.

7. Verbrugghe M, Verhaeghe S, Lauwaert K, Beeckman D, Van Hecke A. Determinants and associated factors influencing medication adherence and persistence to oral anticancer drugs: a systematic review. Cancer Treat Rev. 2013;39(6):610-621. doi:10.1016/j.ctrv.2012.12.014 
8. Weingart SN, Li JW, Zhu J, et al. US cancer center implementation of ASCO/Oncology Nursing Society chemotherapy administration safety standards. J Oncol Pract. 2012;8(1):7-12. doi:10.1200/ JOP.2011.000379

9. Hamine S, Gerth-Guyette E, Faulx D, Green BB, Ginsburg AS. Impact of mHealth chronic disease management on treatment adherence and patient outcomes: a systematic review. $J$ Med Internet Res. 2015;17(2):e52. doi:10.2196/jmir.3951

10. Whittaker R, Merry S, Dorey E, Maddison R. A development and evaluation process for mHealth interventions: examples from $\mathrm{New}$ Zealand. J Health Commun. 2012;17(Supp1):p11-21. doi:10.1080/ 10810730.2011.649103

11. Darlow S, Wen KY. Development testing of mobile health interventions for cancer patient self-management: a review. Health Informatics J. 2016;22(3):633-650. doi:10.1177/1460458215577994

12. World Health Organization. mHealth: New Horizons for Health Through Mobile Technologies: Based on the Findings of the Second Global Survey on eHealth (Global Observatory for eHealth Series, Volume 3). World Health Organization; 2011. Available from: https://www.who.int/goe/publications/goe mhealth_web.pdf. Accessed October 2019.

13. Mohr DC, Schueller SM, Montague E, Burns MN, Rashidi P. The behavioral intervention technology model: an integrated conceptual and technological framework for eHealth and mHealth interventions. J Med Internet Res. 2014;16(6). doi:10.2196/jmir.3077

14. Skrabal Ross X, Gunn KM, Patterson P, Olver I. Mobile-based oral chemotherapy adherence-enhancing interventions: scoping review. JMIR Mhealth Uhealth. 2018;6(12):e11724. doi:10.2196/11724

15. Kardas P, Lewek P, Matyjaszczyk M. Determinants of patient adherence: a review of systematic reviews. Front Pharmacol. 2013;(2013(4):91.

16. Corrente J. Oral Chemotherapy, A Tough Pill to Swallow: A Systematic Review [Internet]. Rode Island College; 2016. Available from: https:// digitalcommons.ric.edu/etd/143/. Accessed February 2018.

17. Geissler J, Sharf G, Bombaci F, et al. Factors influencing adherence in CML and ways to improvement: results of a patient-driven survey of 2546 patients in 63 countries. J Cancer Res Clin Oncol. 2017;143 (7):1167-1176. doi:10.1007/s00432-017-2372-z

18. Muluneh B, Deal A, Alexander MD, et al. Patient perspectives on the barriers associated with medication adherence to oral chemotherapy. J Oncol Pharm Pract. 2018;24(2):98-109. doi:10.1177/1078155216 679026
19. Vervloet M, Linn AJ, van Weert JC, de Bakker DH, Bouvy ML, van Dijk L. The effectiveness of interventions using electronic reminders to improve adherence to chronic medication: a systematic review of the literature. J Am Med Inform Assoc. 2012;19(5):696-704. doi:10. 1136/amiajnl-2011-000748

20. Simons S, Ringsdorf S, Braun M, et al. Enhancing adherence to capecitabine chemotherapy by means of multidisciplinary pharmaceutical care. Support Care Cancer. 2011;19(7):1009-1018. doi:10. 1007/s00520-010-0927-5

21. Spoelstra SL, Given BA, Given $\mathrm{CW}$, et al. An intervention to improve adherence and management of symptoms for patients prescribed oral chemotherapy agents: an exploratory study. Cancer Nurs. 2013;36(1):18-28. doi:10.1097/NCC.0b013e3182551587

22. Spoelstra SL, Given CW, Sikorskii A, et al. Feasibility of a text messaging intervention to promote self-management for patients prescribed oral anticancer agents. Oncol Nurs Forum. 2015;42 (6):647-657. doi:10.1188/15.ONF.647-657

23. Ziller V, Kyvernitakis I, Knoll D, Storch A, Hars O, Hadji P. Influence of a patient information program on adherence and persistence with an aromatase inhibitor in breast cancer treatment - the COMPAS study. BMC Cancer. 2013;13:407. doi:10.1186/1471-2407-13-407

24. Gebbia V, Bellavia M, Banna GL, et al. Treatment monitoring program for implementation of adherence to second-line erlotinib for advanced non-small-cell lung cancer. Clin Lung Cancer. 2013;14 (4):390-398. doi:10.1016/j.cllc.2012.11.007

25. Braun V, Clarke V. Using thematic analysis in psychology. Qual Res Psychol. 2006;3(2):77-101. doi:10.1191/1478088706qp063oa

26. Kav S, Schulmeister L, Nirenberg A, Barber L, Johnson J, Rittenberg C. Development of the MASCC teaching tool for patients receiving oral agents for cancer. Support Care Cancer. 2010;18 (5):583-590. doi:10.1007/s00520-009-0692-5

27. Given CW, Given BA, Sikorskii A, et al. Deconstruction of nurse-delivered patient self-management interventions for symptom management: factors related to delivery enactment and response. Ann Behav Med. 2010;40(1):99-113. doi:10.1007/s12160-010-9191-7

28. Michie S, Richardson M, Johnston M, et al. The behavior change technique taxonomy (v1) of 93 hierarchically clustered techniques: building an international consensus for the reporting of behavior change interventions. Ann Behav Med. 2013;46(1):81-95. doi:10. 1007/s12160-013-9486-6
Patient Preference and Adherence

\section{Publish your work in this journal}

Patient Preference and Adherence is an international, peer-reviewed, open access journal that focusing on the growing importance of patient preference and adherence throughout the therapeutic continuum. Patient satisfaction, acceptability, quality of life, compliance, persistence and their role in developing new therapeutic modalities and compounds to optimize clinical outcomes for existing disease states are major areas of interest for the journal. This journal has been accepted for indexing on PubMed Central. The manuscript management system is completely online and includes a very quick and fair peer-review system, which is all easy to use. Visit http:// www.dovepress.com/testimonials.php to read real quotes from published authors. 